Ensaio

\title{
Algumas reflexões sobre os impactos sofridos pelos sistemas didáticos em tempos de pandemia
}

\author{
Some reflections on the impacts suffered by the didactic systems in pandemic times
}

\author{
Algunas reflexiones sobre los impactos que sufren los sistemas didácticos en tiempos de \\ pandemia
}

\author{
Jany Santos Souza Goulart ${ }^{1}$ \\ iD [0000-0002-9140-0223] \\ Luiz Marcio Santos Farias ${ }^{2}$ \\ [0000-0002-2374-3873] \\ Claudiano Goulart ${ }^{3}$ \\ [0000-0002-8745-8406]
}

\begin{abstract}
Resumo
Neste artigo, convidamos o leitor a refletir sobre as transformações a que foram submetidos os Sistemas Didáticos - SD em tempos de confinamento social. As argumentações são construídas a partir da noção de Sistemas Didáticos Principais - SDP atrelados aos Sistemas Didáticos Auxiliares - SDA e aos Sistemas Didáticos Induzidos - SDI, face às repercussões desencadeadas pelas funções didáticas: cronogênese, mesogênese e topogênese, presentes no seio da Teoria Antropológica do Didático - TAD, em contexto pandêmico. Assim, o estudo objetiva apontar caminhos que despertem um olhar diferenciado sobre o cenário educacional emergente que se desenhou por meio de um trânsito abrupto da Educação Presencial para os entretons de um Ensino Remoto. Os direcionamentos metodológicos do trabalho assumem uma vertente teórica descritiva inspirada em uma teleaula do projeto Escola em Casa do Distrito Federal - DF vinculada às inquietações que reverberam na esfera midiática. Enquanto proposta de intervenção, acreditamos que o momento se apresenta como oportuno para a elaboração de Projetos de Estudo e Pesquisa que contemplem a integração famíliaescola.
\end{abstract}

Palavras-chave: Sistemas Didáticos. Funções Didáticas. Teoria Antropológico do Didático. Pandemia.

\begin{abstract}
In this article, we invite the reader to reflect on the transformations that the Didactic Systems - DS were submitted in times of social confinement. The arguments are built from the notion of Principal Didactic Systems - PDS linked to Auxiliary Didactic Systems - ADS and Induced Didactic Systems - IDS, in view of the repercussions triggered by didactic functions: chronogenesis, mesogenesis and

\footnotetext{
${ }^{1}$ jssgoulart@uefs.br, Doutora em Ensino, Filosofia e História das Ciências pela UFBA/UEFS, Professora Assistente B, Universidade Estadual de Feira de Santana (UEFS), Feira de Santana/Bahia/Brasil.

2 Imsfarias@ufba.br, Doutor em Didática da Matemática pela UM2 (França), Professor Adjunto, Universidade Federal da Bahia (UFBA), Salvador/Bahia/Brasil.

${ }^{3}$ cgoulart@uefs.br, Doutor em Matemática pela UnB, Professor Titular A, Universidade Estadual de Feira de Santana (UEFS), Feira de Santana/Bahia/Brasil.
} 
topogenesis, present within the Anthropological Theory of the Didactic - ATD, in a pandemic context. Thus, the study aims to point out paths that awaken a differentiated look at the emerging educational scenario that was designed through an abrupt transit of Presential Education to the various shades of Distance Education. The methodological directions of the work assume a theoretical descriptive aspect inspired by a teleclass of the School at Home project of the Federal District - FD linked to the concerns that reverberate in the media sphere. As an intervention proposal, we believe that the moment presents itself as opportune for the elaboration of Study and Research Projects that contemplate the family-school integration.

Keywords: Didactic Systems. Didactic Functions. Anthropological Theory of Didactics. Pandemic.

\section{Resumen}

En este artículo, invitamos al lector a reflexionar sobre las transformaciones a las que fueron sometidos los Sistemas Didácticos -SD- en tiempos de encierro social. Los argumentos se construyen a partir de la noción de Sistemas Didácticos Principales - SDP vinculados a los Sistemas Didácticos Auxiliares - SDA y a los Sistemas Didácticos Inducidos - SDI, frente a las repercusiones desencadenadas por las funciones didácticas: cronogénesis, mesogénesis y topogénesis, presentes en el seno de la Teoría Antropológica de lo Didáctico - TAD, en contexto pandémico. Así, el estudio tiene como objetivo apuntar caminos que despierten una perspectiva diferente sobre el escenario educativo emergente que se ha diseñado mediante un tránsito abrupto de la Educación Presencial a los varios tonos de una Enseñanza Remota. Las orientaciones metodológicas del trabajo asumen una vertiente teórica descriptiva inspirada en una teleclase del proyecto Escuela en Casa en el Distrito Federal - DF vinculada a las inquietudes que reverberan en la esfera mediática. Como propuesta de intervención, creemos que el momento se presenta oportuno para la elaboración de Proyectos de Estudio e Investigación que contemplen la integración familia-escuela.

Palabras claves: Sistemas Didácticos. Funciones Didácticas. Teoría Antropológica de la Didáctica. Pandemia.

\section{Introdução}

A propagação da doença causada pelo novo Coronavírus (COVID - 19) ditou regras e exigiu de todos nós atitudes que viessem a contribuir para mitigação do avanço acelerado da doença. Dentre elas, citamos o isolamento social que limitou a liberdade de locomoção, direito inviolável nos termos do artigo 5o da Constituição Federal de 1988, frente a essa Emergência de Saúde Pública, caracterizada pela Organização Mundial da Saúde - OMS (2020) como uma pandemia. Neste sentido, o contexto delineado contrapôs, incisivamente, às relações e características sociais próprias dos seres humanos, as quais foram suprimidas e atenuadas neste momento. O plano estratégico divulgado pela WHO (2020), pontua alguns dos reflexos, advindos da pandemia, pelos quais a população mundial foi submetida,

A pandemia da doença de Coronavírus 2019 (COVID-19) está cobrando um preço enorme para indivíduos, famílias, comunidades e sociedades em todo o mundo. A vida cotidiana mudou profundamente, as economias entraram em recessão e muitas das redes tradicionais de socialização, econômica e de saúde pública, nas quais muitas pessoas confiam em tempos difíceis, foram submetidas a uma pressão sem precedentes. (WHO, 2020, p.2, tradução nossa ${ }^{4}$ )

4 "The coronavirus disease 2019 (COVID-19) pandemic is exacting a huge toll on individuals, families,
communities, and societies across the world. Daily lives have been profoundly changed, economies have fallen 
Os impactos são imensuráveis e repercutem também no âmbito educacional com o fechamento das instituições de ensino, centros de atividades sociais e interação humana. Segundo dados da Unesco mais de $90 \%$ dos estudantes do mundo foram afetados e projeções mais drásticas pairam no horizonte, de acordo com a Comissão Internacional sobre os Futuros da Educação ${ }^{5}$ cuja missão é preparar um relatório global sobre os pósteros da educação (UNESCO, 2020).

Os reflexos da crise causada pela COVID-19 indicam uma emergente recessão econômica que colocará em evidência e potencializará as discrepâncias sociais. De acordo com a Comissão há indicativo de retração no avanço do progresso obtido na expansão do acesso educacional e na melhoria da qualidade da aprendizagem em todo o mundo (UNESCO, 2020). Frente a essas questões, as primeiras propostas apontaram para um formato híbrido de ensino objetivando a integração entre o presencial e o virtual no retorno gradual das atividades.

Contudo, em meio à pandemia, o cenário que nos foi imposto consistiu na transferência das atividades que eram realizadas em salas de aulas, protagonizadas por professores e alunos, para aulas virtuais que ocorrem, geralmente, no seio familiar via plataformas digitais ou tele aulas, com a imposição de desafios de diferentes naturezas. Frente a esse viés, Valle e Marcom (2020) destacam que,

A crise instaurada pela Covid 19 produziu nas escolas um cenário de muitas mudanças. Nesta esteira, apresentamos como um dos maiores desafios a imposição da exigência de um novo perfil que devem ter os professores para ministrar aulas nesse contexto de contradições vivenciadas dentro e fora do espaço escolar. (VALLE, MARCOM, 2020, p.142)

Neste contexto, foi revelado o seguinte questionamento: como analisar os Sistemas Didáticos - SDs emergentes, por meio de recombinações praxeológicas, na perspectiva de isolamento social? Uma projeção da resposta reside na análise do funcionamento dos Sistemas Didáticos - SDs aditado ao estudo do comportamento das funções didáticas em situação de reclusão, assim como se pode delinear para tempos futuros com a atenuação ou extinção desta realidade.

Em outras palavras, o antes, o durante e inferências para o depois estruturarão o texto, à luz da Teoria Antropológica do Didático - TAD (CHEVALLARD, 1996; 1998; 1999; 2001a; 2006), inscrita no projeto de modelização das práticas humanas, fornecendo elementos que possibilitarão descrever contornos do novo desenho praxeológico ${ }^{6}$ que irá se instaurar. A partir desse limiar, é possível indagar também sobre os novos papéis assumidos por estudantes, professores e familiares nesses espaços.

Assim o texto é estruturado em quatro partes. No primeiro tópico, situaremos o leitor acerca de alguns objetos teóricos da Teoria Antropológica do Didático - TAD. O funcionamento

into recession, and many of the traditional social, economic, and public health safety nets that many people rely on in times of hardship have been put under unprecedented strain."

5 Presidida pelo presidente da Etiópia, Sahle-Work Zewde, a Comissão Internacional sobre os Futuros da Educação reúne pensadores líderes das áreas de política, universidades, sociedade civil, educação e empresas privadas.

${ }^{6}$ O termo praxeológico advém da palavra praxeológia, proveniente da junção das palavras gregas práxis e logos, a qual constituiu o principal pilar da Teoria Antrpológica do Didático - TAD apresentando uma estrutura composta pelo quadruplo $[T ; \tau ; \theta ; \Theta]$, em que $T$ é o tipo de tarefas, $\tau$ é a técnica utilizada na resolução de $T, \theta$ o discurso que fundamenta a técnica $\tau$ respalda por uma teoria $\Theta$. 
dos Sistemas Didáticos comporá o segundo tópico. Em seguida dedica-se especial atenção para o que é vivenciado hoje com as alterações e recombinações praxeológicas por meio do trânsito transpositivo que fragmenta e dilui os Sistemas Didáticos Principais - SDP em Sistemas Didáticos - SDA e Sistemas Didáticos Induzidos - SDI. Na quarta parte, frente a este contexto, apresentaremos nossas expectativas para o futuro no âmbito educacional, além de elencarmos algumas hipóteses que podem inspirar novos estudos.

\section{Alguns objetos da Teoria Antropológica do Didático - TAD}

No universo estrutural da TAD (CHEVALLARD, 1996; 1998; 1999; 2001a; 2006), a premissa basilar é que tudo pode ser caracterizado como objeto. Assim, abordaremos apenas alguns elementos, a saber, aqueles que servirão de aporte para fundamentar e modelar a discussão proposta neste texto. Neste sentido, os alicerces teóricos assumem graus hierárquicos, a começar pelos termos primitivos "pessoas $X$ e as instituições I, bem como as entidades restantes que serei levado a introduzir, são, pois, objetos de um tipo particular" (CHEVALLARD, 1996, p. 127), os quais são "material de base" da construção teórica considerada.

A partir desse pilar, Chevallard (1999) admitiu que os respectivos conceitos: os objetos $O$, as pessoas $X$ e as instituições $I$, estão na gênese e ordenam sua construção teórica. Neste limiar, a condição de existência dos objetos se condiciona à adoção destes, ou seja, eles passarão a existir, no momento em que foram discernidos pelas "pessoas $X$ ou instituição $I$. Com isso, emergirão as relações "pessoal" e "institucional" denotadas por $R(X, O)$ e $R(I, O)$ " (CHEVALLARD, 1998, p.93), respectivamente, o que tornam perceptivos os aspectos de interdependência entre esses elementos.

Em complementação, Chevallard (1998, p.14) destaca que "toda ação humana procede de uma praxeologia”. E essa organização praxeológica é estruturada,

(...) em torno de um tipo de tarefas $T$, que encontramos em princípio, um tripleto formado de uma técnica (pelo menos), $\tau$, de uma tecnologia de $\tau, \theta$ e uma teoria de $\theta, \Theta$. O conjunto, denotado [T/ $\tau / \theta / \theta]$, constitui uma praxeologia específica, este qualificador significa que se trata de uma praxeologia relacionada a um único tipo de tarefas, T. (CHEVALLARD, 1998, p. 5 , tradução nossa ${ }^{7}$ ).

O detalhamento desta praxeologia pontual, centrada em torno de um tipo de tarefa $T$ pode ser descrita da seguinte forma: "uma parte prático-técnica $\Pi=[T / \tau]$, ou práxis (o qual pode, se for caso disso, ser chamada de "saber fazer") e uma parte tecnológica-teórica $\Lambda=$ $[\theta / \Theta]$, ou logos (que podemos identificar como um "saber" no sentido usual do termo)." (CHEVALLARD, 2018, p.34). É relevante destacar que segundo este autor, os dois blocos são indissociáveis, pois "não há práxis que não sejam acompanhadas de um logos" (Ibid., p.34). 0 contexto vivenciado pode ser modelado por uma praxeologia $\Pi \oplus \Lambda=[T / \tau / \theta / \Theta]$ existente em uma instituição de ensino na modalidade presencial, a qual denotaremos por $I_{E P}$, que sofreu recombinações praxeológicas ao ser transposta para uma outra instituição de ensino

\footnotetext{
7 “(...) autour d'un type de tâches $T$, on trouve ainsi, en principe, un triplet formé d'une technique (au moins), $\tau$, $d^{\prime}$ une technologie de $\tau, \theta$, et d'une théorie de $\theta, \Theta$. Le tout, noté $[T / \tau / \theta / \Theta]$, constitue une praxéologie ponctuelle, ce qualificatif signifiant qu'il s'agit d'une praxéologie relative à un unique type de tâches, T. Une telle praxéologie - ou organisation praxéologique - est donc constituée d'un bloc pratico-technique, [T/ $\tau]$, et d'un bloc technologico-théorique, $[\theta / \Theta]^{\prime \prime}$.
} 
na modalidade virtual dita $I_{E V}^{*}$. Nestes termos Chevallard (2018, p. 35) destaca que "a praxeologia transposta $(\Pi \oplus \Lambda)^{*}$ poderia, por vezes, igualmente ser escrita $\left(\Pi^{*}\right) \oplus \Lambda$ com um logos mantido, mas uma práxis modificada, (...)".

A partir dessa perspectiva, é possível evidenciar o surgimento de novas restrições, por exemplo o distanciamento social o qual se atrela às diferenciadas condições que reconfiguraram os SDs para o campo virtual, agora em funcionamento no seio familiar, o qual se apresenta como um fenômeno transpositivo das organizações praxeológicas, visto que a práxis foi substancialmente alterada desencadeando modificações no "saber fazer". Isso observado, enfatiza-se no quadro da TAD que "uma pessoa x é o resultado de sujeições passadas e presentes." (CHEVALLARD, 2018, p.37).

Dito isto, podemos considerar que todos os sujeitos vinculados às instituições educacionais tiveram que alterar seus "fazeres e gestos", o que resulta na exploração de novas sujeições que refletem na dinâmica praxeológica. De acordo com Chevallard,

(...) uma dinâmica praxeológica pela qual o equipamento praxeológico de $\mathrm{x}$, que podemos denotar $\mathrm{EP}(\mathrm{x})$, muda - uma parte deste equipamento perde seu caracter operacional enquanto outras partes dele são renovadas e outros elementos são adicionados ao longo do tempo. (CHEVALLARD, 2018, p.37)

Desta forma, é possível conceber que o advento da suspensão das aulas provocou modificações no funcionamento dos Sistemas Didáticos- SDs instaurados nas diversas salas de aulas, os quais foram destituídos de suas praxeologias provocando transformações e desequilíbrios no processo de ensino e aprendizagem. Significa dizer que, o gerenciamento e intervenções dos professores agregadas às interações dos estudantes em torno de um saber, sob o qual deveria existir um processo comunicacional, foi silenciado no campo presencial e múltiplas vozes ecoaram no domínio virtual.

\section{O funcionamento dos Sistemas Didáticos - SDs}

Antes de retratar o funcionamento dos Sistemas Didáticos - SDs é pertinente descrevêlos no âmbito da Didática. Já que, segundo Brousseau (2008) são constituídos pelas relações estabelecidas entre três elementos: "o conteúdo de ensino (saber), o estudante e o professor, representado por meio de um diagrama triangular, denominado triângulo didático. Esquematicamente, em cada vértice da figura são posicionados os sujeitos de ação (estudante - professor) e o saber. Segundo Brousseau (2008, p.16), "esse esquema é associado a uma concepção de ensino em que o professor organiza o conhecimento a ser transmitido em uma série de mensagens, das quais o aluno toma para si o que deve adquirir".

No entanto, a recorrência representacional de um triângulo equilátero sugere interpretações de equilíbrios entre as relações: (professor - saber), (professor - estudantes) e (estudantes - saber), o que caracteriza, de certa forma, uma estabilidade com contornos utópicos. Nestes termos, Nascimento et al. (2019) sinaliza a existência de instabilidades nas funções dos agentes que integram os sistemas de ensino. E a partir dessa concepção, é viável apresentar um redesenho do esquema ao utilizar um triângulo escaleno para representar que as interações didáticas não ocorrem de forma simétrica e regular.

Aspecto este respaldado pela Teoria Antropológica do Didático - TAD, ao interpretar que os Sistemas Didáticos atuam em termos de condições e restrições, as quais podem ser importadas pelos alunos $X$, professores $Y$ ou obra $O$ estudada. $O$ que ressalta a ausência de equilíbrios entre as relações que configuram os mesmos. Neste sentido, por intermédio desta 
concepção Chevallard (2011, p.124) pontua que "as grandes linhas do modelo geral proposto pela TAD é funcionamento de um sistema didático $S(X ; y ; O)$ ".

Nesta perspectiva, as relações que se estabelecem dentro de um Sistema Didático SD constituído, em parte, por professores - estudantes estão subordinadas a certas regras e convenções associadas, metaforicamente, às cláusulas de um contrato didático, manifestado principalmente quando há a transgressão por um dos parceiros da relação didática. No entanto, no momento em que ocorrem rupturas, é como se cláusulas de um contrato, implícito, fossem cumpridas e unisse professor e alunos:

Surpresa e revolta do aluno, que não sabe resolver o problema, e surpresa também do professor, que considera seus serviços prestados razoavelmente suficientes. Produz-se, assim, uma crise, que origina a renegociação e busca de um novo contrato em função de novos conhecimentos" (CHEVALLARD, BOSCH e GASCÓN, 2001a, p.220).

Todavia, o que desejamos ressaltar, sobretudo, é que a ruptura contratual, neste caso, foi impulsionada por um fator externo à relação professor-aluno-saber. Neste caso, a COVID19 foi o agente motivador da quebra do contrato didático e consequente diluição dos Sistemas Didáticos - SDs a ocasionar uma abrupta interrupção em todos os acordos educacionais estabelecidos mundialmente, ou seja, tudo que estava instaurado nos sistemas de ensino foram, subitamente, dissolvidos e o que se revelou como um dos fatores para o protagonismo de outros SDs.

\section{Configurações entre Sistemas Didáticos Principal - SDP e os Sistemas Didáticos - SDs emergentes em tempos de pandemia}

Inquietações de diferentes naturezas circundam os funcionamentos dos Sistemas Didáticos emergentes, geralmente guiadas por indagações. Dentre elas podemos citar: será que os estudantes estão aprendendo? As aulas virtuais ou tele aulas são eficazes? Como enfrentar os desafios vinculados a essa imigração digital em tempos de pandemia? É relevante destacar que não é o objetivo deste texto apresentar respostas às questões elencadas, mas concebemos que no âmago destas estão os atores dos SDs, face a face com inúmeras mudanças que precisam ser analisadas no âmbito praxeológico dos sistemas de ensino atrelados às funções didáticas.

O primeiro ponto é que, em sentido amplo, um Sistema Didático- SD se forma cada vez que algumas pessoas se defrontam com uma questão, cuja resposta não seja evidente e decidem fazer algo para resolvê-la. Especificamente, essas questões, tarefas ou atividades pertencentes a determinado campo de conhecimento incorporado a certa instituição educacional inerentes aos diversos níveis, seja da Educação Infantil ao Ensino Superior são reguladas por praxeologias operacionalizadas pelos atores institucionais. Dito de outra forma, um saber deve ser estudado, explorado, analisado e desenvolvido pelos sujeitos (professor estudantes) em aulas presenciais.

Contudo, a disseminação acelerada do novo Coronavírus, alterou a estrutura praxeológica dos Sistemas Didáticos Principais - SDP. Assim, fundamentado nos estudos de Chevallard (2011) é pertinente descrever que as atividades presenciais que eram desenvolvidas em classes $[X ; y]$ a partir do seguinte modelo: $Y=\{y\} \rightarrow S(X ; y ; O)$ ou de forma mais explícita, $X=\left\{x_{1}, x_{2}, \ldots, x_{n}\right\} \rightarrow S\left(x_{1}, x_{2}, \ldots, x_{n} ; y ; O\right\}$, o que significa um professor 
$y$, dito diretor ou coordenador de estudo, orientava presencialmente um grupo de alunos, $X=\left\{x_{1}, x_{2}, \ldots, x_{n}\right\}$ a estudar a obra ${ }^{8} O$ no intuito de conhecê-la. Tem-se um agrupamento de pessoas que compartilham esforços e conhecimentos e formam, assim, uma comunidade de estudo.

No entanto, frente aos desafios e restrições que se impuseram aos Sistemas Didáticos Principais - SDP, se ergueu a configuração de outros SDs, dentre eles elencamos os Sistemas Didáticos Auxiliares - SDA, os quais podem ser modelados por $S(X ; \emptyset ; O)$, denotados por Chevallard, Bosch e Gascón (2001a, p. 195) como "Sistemas Autodidáticos", e os Sistemas Didáticos Induzidos - SDI descritos por $S\left(X ; y^{*} ; O\right)$ quando da assunção por pais e familiares ou responsáveis da função de professor.

Nestes termos, a emergência de um novo formato educacional alterou substancialmente as práxis dos sujeitos envolvidos neste processo. Os termos virtual, remoto, à distância, dentre outros, integram os diálogos hodiernos de coordenadores pedagógicos, professores, estudantes e familiares, a partir da "transferência das instituições de ensino para o seio familiar". Os responsáveis e familiares agora são partícipes ativos desse processo de ensino e aprendizagem. Neste sentido, inúmeras restrições educacionais afloram pautadas em ferramentas tecnológicas. Nestes termos, Luc Trouche (2020) descreve alguns desses desafios.

Hoje, muitos professores em todo o mundo ensinam em casa, usando plataformas digitais. Não é tão fácil, nem para eles nem para os estudantes. Na minha opinião, existem condições para enfrentar esses novos desafios. A primeira condição diz respeito aos recursos dos professores. Os livros didáticos, sem dúvida, não são mais suficientes. É preciso a criatividade de professores e alunos para projetar novos recursos que possam suportar interações de longa distância. (...) (TROUCHE, 2020, p.2, tradução nossa ${ }^{9}$ )

Ao apontar algumas das limitações que se instauraram, no período de pandemia no campo educacional, Trouche (2020) também aponta caminhos que inspiram ações e projetam soluções, dentre as quais citamos a criação de novos recursos que estejam imunes às limitações provocadas pelo distanciamento social, assim como a promoção e compartilhamento dos mesmos, sem perder de vista a garantia dos laços educacionais imbricados às reduções de desigualdades, ou seja, "dá meios para quem tem menos" (TROUCHE, 2020, p.1).

Contudo, pensamos que antes de nos apoiarmos na criatividade de professores e estudantes no intuito de projetar novos recursos é pertinente compreender as modificações das funções didáticas (mesogênese, topogênese e cronogênese), visto que cada sujeito passa a ter uma incumbência diferenciada das que foram estabelecidas na configuração dos SDs presenciais. A título de exemplo, recorremos a uma tele aula que abordou o tema: figuras geométricas. O vídeo hospedado no Youtube possui mais de 18 mil visualizações e integra as ações do governo do Distrito Federal, tido como um primeiro passo do projeto emergencial de educação à distância.

\footnotetext{
${ }^{8} \mathrm{Na}$ TAD são sinônimos de obra (atividades, questões, tarefas, etc.)

${ }^{9}$ Many teachers around the world today teach from home, using digital platforms. It is not so easy, neither for them nor for the students. In my opinion, there are four conditions for meeting these new challenges. The first condition concerns teachers' resources. Textbooks, no doubt, are no longer enough. It takes the creativity of teachers and students to design new resources that can support long-distance interactions. (...)
} 
No primeiro momento da gravação da aula, a professora se apresenta e convida todos os estudantes para uma conversa sobre figuras geométricas e complementa:

- Vamos aproveitar o nosso tempo enquanto estamos em casa. Não é mesmo? Isso!

- E antes da gente conversar sobre formas geométricas. Eu quero combinar com vocês, que ao longo da minha conversa, eu vou fazer algumas perguntas, quero que vocês fiquem bem atentos para responder todas elas. Combinado?

- Eu pergunto daqui vocês respondem daí e a gente faz uma aula juntos. Combinado?

- Então vamos lá.

(SEEDF, 2020, não paginado).

A docente, em sua fala, revela elementos implícitos do contrato didático, ou seja, ao convidar todos os estudantes (agora telespectadores) para uma conversa, em termos contratuais, intenta-se manter as cláusulas que foram estabelecidas para o formato das aulas presenciais, aspecto este que não se verifica, pois, as trocas instantâneas entre professor e alunos foram interrompidas nessa modalidade. $\mathrm{E}$ a aula continua, como uma metáfora de um "diálogo no espelho", situação em que o próprio professor responde às próprias perguntas (FARIAS, 2010, p.202). Neste caso, especifico, a professora simula ouvir as respostas dos alunos, como em um "faz de conta".

A partir da observação desse trecho, é possível identificar alterações no meio mesogênese (CHEVALLARD, 2009, p.79) que antes da pandemia situava-se em ambientes escolares com interações diretas entre os sujeitos da comunidade escolar. Assim, como as regulações dos tempos cronológicos e didáticos (cronogênese) (Ibid., p.79) foram remodelados e o papel que estudantes e professores passaram a ocupar não são mais os mesmos (topogênese) (Ibid., p.79) , no tocante à organização matemática (OM) construída ou em processo de construção.

Atrelada às condições e restrições inerentes ao processo, pode-se citar que o meio no qual aconteciam as aulas foi transladado para o ambiente onde residem professores e estudantes. Os topos ${ }^{10}$ dos sujeitos foram metamorfoseados rompendo com a visão monopolizada do professor como "aquele que ensina" e do aluno como "aquele que aprende o que lhe é ensinado" podendo evoluir para uma concepção na qual os papéis de professor e de aluno são definidos de maneira menos rígidos, o que produz, assim desequilíbrios nas responsabilidades atribuídas tradicionalmente tanto para o professor como para o aluno. "O professor já não tem que decidir a cada instante qual será a atividade pontual dos alunos e deixa de ser considerado como o único (e principal) responsável pela atitude, motivação e tarefa deles." (CHEVALLARD, BOSCH e GASCÓN, 2001a, p.201).

Pautados em Chevallard (2009) podemos admitir que a administração da cronogênese, função que regula os tempos didáticos, nos SDA e SDI, nos parece mais flexível do que nos SDPs. Desenvolver tarefas no seio do ambiente familiar, geralmente, não tem limites temporais pré-estabelecidos. Por outro lado, os professores perdem o topos de supervisores e gestores do tempo didático nos SDs emergentes, pois esta função passa a ser assumida pelos estudantes, pais ou responsáveis. A partir desta configuração, torna-se evidente que o advento da COVID- 19 alterou substancialmente o desenho e funcionamento dos Sistemas

\footnotetext{
${ }^{10}$ A topogênese, tem sua origem advinda do grego topos (que corresponde ao locus latino) que significa lugar. Ver Chevallard (1998).
} 
Didáticos em correlação às respectivas funções didáticas que modelizam as ações didáticas dentro dos SDs.

\section{Projeções e apostas didáticas de ensino e pesquisa em tempos de pandemia e pós- pandemia}

A partir das limitações inerentes aos cenários educacionais, as quais nos foram impostas pelo distanciamento e isolamento social no intuito de mitigar a propagação do vírus, é possível caracterizá-las em termos de restrições e condições como definidas por Chevallard (2018, p. 35), respectivamente: “ uma restrição é uma condição observada, de uma certa posição institucional a um certo instante, como não modificável, imutável (relativamente e provisoriamente); da mesma forma, uma condição é uma restrição modificável neste mesmo sentido. "Neste aspecto, abrem-se possibilidades de recombinações praxeológicas (CHEVALLARD, 2018), visto que podemos pensar em media-las por Percursos de Estudos e Pesquisas - PEP ${ }^{11}$ (CHEVALLARD,2009) numa vertente colaborativa escola-família.

É relevante destacar também que de acordo com Chevallard (2009) os Percursos de Estudo e Pesquisa são dispositivos didáticos e metodológico originário do sistema de ensino francês, inspirados pelos Travaux Personnels Encadrés (TPE) (CHEVALLARD, 2001b) que visavam desenvolver, nos estudantes, competências autônomas ao realizar pesquisas em grupos ou individualmente e saber usá-las com relevância. Pautado nesta linha de pensamento, este autor teoriza as Atividades de Estudo e Pesquisas - AEP e posteriormente amplia para os PEPs.

Os PEPs alicerçam-se no Paradigma de Questionamento do Mundo (CHEVALLARD, 2012) que envolvem diálogos investigativos que rompem com a leitura invariante do universo dos saberes. Essa mudança de perspectiva impacta os Sistemas Didáticos - SDs, tendo em vista que cada autor de $S(X ; y ; O)$ necessita saber seu papel e ter meios para exercê-los, o que envolve um sistema de condições a ser criado. De acordo com Chevallard (2009) a modelização desta organização didática pode ser escrita da seguinte forma: $S(X ; y ; Q) \rightarrow \mathrm{R}$. O que significa dizer que, os estudantes $X$ investigarão determinada questão $Q$ sob a direção de $y$ no intuito de dar uma resposta $R$ à $Q$. Para isso, o $S(X ; y ; Q)$ exige ferramentas e recursos de diferentes naturezas que comporão o meio didático $M$ que deve identificar, agrupar, aprender a utilizar a fim de produzir $R$, denotado por: $[S(X ; y ; Q) \rightarrow M] \rightarrow R$.

Neste sentido, inferimos que propostas didáticas pensadas e estruturadas, segundo este viés, promoverão movimentações nas funções didáticas dos sujeitos imersos nos Sistemas Didáticos que constituirá um caminho promissor para o enfretamento da problemática instaurada neste contexto pandêmico. Assim, esquematicamente a modelização dos Sistemas Herbatiano ${ }^{12}$ Reduzidos e Semidesenvolvidos, que podem entrar em funcionamento.

Quadro 1 - Exemplos de Sistemas Didáticos Herbatiano

\begin{tabular}{|c|c|}
\hline Sistemas Herbatiano Reduzidos & Sistemas Herbatiano Semidesenvolvidos \\
\hline $\mathrm{S}\left(\mathrm{X} ; \mathrm{y}^{*} ; \mathrm{Q}\right) \rightarrow R^{\bullet}$ & {$\left[\mathrm{S}\left(\mathrm{X} ; \mathrm{y}^{*} ; \mathrm{Q}\right) \rightarrow \mathrm{M}\right] \rightarrow \mathrm{R}^{\bullet}$} \\
$\mathrm{S}(\mathrm{X} ; \emptyset ; \mathrm{Q}) \rightarrow R^{\bullet}$ & {$[\mathrm{S}(\mathrm{X} ; \emptyset ; \mathrm{Q}) \rightarrow \mathrm{M}] \rightarrow \mathrm{R}^{\bullet}$} \\
\end{tabular}

\footnotetext{
${ }^{11}$ Em francês Parcours d'Étude et de Recherche - PER.

${ }^{12}$ Com referência ao filósofo e pedagogo Johann Friedrich Herbart (1776-1841). Ver Chevallard (2011, p.131).
} 
Fonte: produção dos autores (2020).

Pautado no meio M que integra os Sistemas Didáticos Herbatianos Semidesenvolvidos ou Desenvolvidos conceituado por Chevallard (2013, p.33) como "um ambiente didático que reúne o conjunto evolutivo de recursos para o estudo de $Q$, um ambiente que é escrito genericamente da seguinte forma: $M=\left\{Q_{1}, \ldots, Q_{n}, R_{1}^{\diamond}, \ldots, R_{n}^{\diamond}, O_{1}, \ldots, O_{n}\right\}$ ", a evolução e transformação do meio ocorre à medida em que os estudantes consultam obras $O$ (livros, textos e materiais de apoio disponível na internet, diálogos com familiares, dentre outros), ou seja, praxeologias reputadas úteis para desconstruir $R^{\natural}$, e extrair nela, eventualmente, materiais e construir com eles ou não a resposta $R$ esperada, denotada por Chevallard (2011; 2013; 2018) por $\mathrm{R}^{\bullet}$.

Contudo, não podemos esquecer que o núcleo de um PEP é uma questão geratriz $Q$ aberta. Em termos de exemplificação recorremos à questão apresentada por Corica (2018, p. 59), " $Q_{0}$ : Existem várias empresas de telefonia celular no mercado e queremos contratar uma, qual escolher?" Problemas desta natureza pode direcionar os estudantes a buscar informações que justifiquem suas escolhas, a estabelecer um plano, a ponderar os pontos positivos e negativos da sua escolha guiados por conjecturas matemáticas que podem ser trabalhadas e desenvolvidas nos encontros síncronos e assíncronos com os professores.

Neste sentido, Chevallard (2002) também sublinha que,

boa parte da atividade dos alunos deve ser dedicada ao estudo e pesquisa da solução de "problemas, (...) para dar vida a uma fórmula, até a "lição de casa", exigindo um esforço mais pessoal, escrito fora da sala de aula e dando origem a um relatório preciso e detalhado.(CHEVALLARD, 2002, p.4)

Não obstante, não podemos desconsiderar a disparidade entre as ferramentas e recursos que os estudantes da rede pública têm acesso frente aos aparatos tecnológicos que os alunos da rede privada de ensino convivem. Disto isto, a elaboração dos Percursos de Estudos e Pesquisa colaborativos deve contemplar estes aspectos. $O$ acesso à internet é o recurso que assevera tais desigualdades neste período vivenciado por todos. Pensando nisto, a esfera midiática vem divulgando mobilizações de governantes em prol de negociações com canais de TV aberta para exibição de aulas e também com uma operadora de celular para disponibilização de chips com pacotes de dados para estudantes da rede pública de ensino. Ações como estas podem atenuar, mesmo que minimamente, tais discrepâncias.

Assim pensamos que, na excepcionalidade da situação vivenciada, o planejamento e execução de Percursos de Estudo e Pesquisa - PEP coordenados pelos professores na roupagem dos SDA e os SDI direcionados por questões são fundamentais para nortear os alunos no estudo e na pesquisa da solução de problemas.

\section{Algumas considerações}

Os protagonistas dos sistemas de ensino estão cercados por inúmeras restrições. É fato. Contudo, enquanto estudiosos da didática, devermos direcionar a nossa atenção para as condições. A primeira condição é que professores e estudantes percebam que, a partir da limitação de convívio social se instaurou uma configuração de ensino diferenciada. Neste contexto, em que os alunos devem assumir uma postura autônoma se revela um momento oportuno para um despertar do ato de questionar o mundo. 
As instituições educacionais devem assumir a missão de estimular e orientar as aprendizagens, em lugar de abandoná-las ao acaso de uma aprendizagem espontânea. E para que isto ocorra é necessário se aproximar de investigações codisciplinares que conduzam os estudantes a assumir um papel questionador, a partir de atividades preconizadas nos moldes dos Percursos de Estudos e Pesquisas - PEP. O desenvolvimento desses dispositivos demanda um trabalho cooperativo em que cada ator do Sistema Didático - SD assume uma função ativa. Em outras palavras, é um coletivo que se esforça a estudar $Q$ e produzir solidariamente uma resposta $\mathrm{R}^{\bullet}$.

A partir da confrontação dos Sistemas Didáticos Principais - SDP e os Sistemas Didáticos Auxiliares - SDA e Sistemas Didáticos Induzidos - SDI é possível identificar caminhos para promover recombinações praxeológicas (CHEVALLARD, 2018) fundamentadas nos Sistemas Didáticos Herbatianos (CHEVALLARD, 2011), permitindo que os estudantes rompam com uma postura estática e coadjuvante e assumam o protagonismo na aquisição de conhecimento. Assim, como proposta de intervenção em prol da elaboração de meios que promovam à aprendizagem, apontam segundo nossa concepção, para um momento oportuno de elaboração de PEP colaborativos (família-escola).

\section{Referências}

BRASIL. [Constituição (1988) ]. Constituição da República Federativa do Brasil de 1988. Brasília, DF: Presidência da República, [2016]. Disponível em: http://www.planalto.gov.br/ccivil_03/Constituicao/ Constituiçao.htm. Acesso em: 20 mai. 2020.

BROUSSEAU, Guy. Introdução ao estudo das situações didáticas: conteúdos e métodos de ensino. Tradução de Camila Bogéa. São Paulo: Ática, 2008.

CHEVALLARD, Yves. Introdução à teoria antropológica do didático. Plan et résumé d'un cours donné du 4 au 13 mai 2011 à l'université Bandeirante de São Paulo (Brésil). 2011. Disponível em : http://yves.chevallard.free.fr/spip/spip/article.php3?id_article=210. Acesso em : 27 mai. 2020.

CHEVALLARD, Yves. Conceitos Fundamentais da Didática: as perspectivas trazidas por uma abordagem antropológica. In: BRUN, Jean. Didática das Matemáticas. Tradução Maria José Figueiredo. Lisboa: Instituto Piaget, 1996.

CHEVALLARD, Yves. Analyse des pratiques enseignantes et didactique des mathématiques: l'approche anthropologique. In: L'UNIVERSITE D'ETE, 1998, p. 91-118. Actes de l'Université d'été La Rochelle. Clermont-Ferrand, France: IREM, 1998. Disponível em:

$<$ http://yves.chevallard.free.fr/spip/spip/IMG/pdf/Analyse_des_pratiques_enseignantes.pdf $>$. Acesso em: 25 out. 2017.

CHEVALLARD, Yves. L' analyse des pratiques enseignantes en théorie antropologique du didactique. Recherches en Didactique des Mathématiques, Grenoble, La Pensée Sauvage Éditions, v. 19, n. 2, p. 221-226, 1999. Disponível em: <http://yves.chevallard.free.fr/spip/spip/IMG/pdf/Analyse_des_pratiques_enseignantes.pdf>. Acesso em: 02 set. 2017. 
CHEVALLARD, Yves. et al. Estudar Matemática: o elo perdido entre o ensino e a aprendizagem. Tradução Daisy Vaz de Moraes. Porto Alegre: Artes Médicas, 2001a.

CHEVALLARD, Yves. Les TPE comme problème didactique. 2001b. Disponível em: < http://yves.chevallard.free.fr/spip/spip/article.php3?id_article=14 >. Acesso em: 14 mai. 2020.

CHEVALLARD, Yves. Organiser l'étude: Ecologie \& régulation, Cours donné à la Xle école d'été de didactique des mathématiques. Paru dans les actes correspondants, La Pensée Sauvage, Grenoble, p. 41-56, 2002. Disponível em: <http://yves.chevallard.free.fr/spip/spip/article.php3?id_article=53>. Acesso em: 17 fev. 2018.

CHEVALLARD, Yves. La théorie anthropologique des faits didactiques devant l'enseignement de l'altérité culturelle et linguistique. Le point de vue d'un outsider. Conférence plénière donnée le 24 mars 2006 au colloque CONSTRUCTION IDENTITAIRE ET ALTÉRITÉ: CRÉATIONS CURRICULAIRES ET DIDACTIQUE DES LANGUES, Université de Cergy-Pontoise, 2006. Disponível em:

$<$ http://yves.chevallard.free.fr/spip/spip/IMG/pdf/La_TAD_devant_I_alterite_culturelle_et_linguistiq ue.pdf>. Acesso em: 13 out. 2017.

CHEVALLARD, Yves. Théorie Anthopologique du Didactique \& Ingénierie Didactique du Développement. In: Journal du Seminaire TAD/IDD - 3; pp. 1-39, 2009. Disponível em: <http://yves.chevallard.free.fr/spip/spip/IMG/pdf/journal-tad-idd-2009-2010-3.pdf>. Acesso em: 06 jul. 2019.

CHEVALLARD, Yves. Teaching Mathematics in Tomorrow's Society: a Case for an Oncoming Counterparadigm. In: INTERNATIONAL CONGRESS ON MATHEMATICAL EDUCATION, 12., 2012, COEX, Seoul, Korea. Seoul: 2012. Disponível em: https://link.springer.com/content/pdf/10.1007\%2F978-3319-12688-3_13.pdf. Acesso em: 10 out. 2017.

CHEVALLARD, Yves. Journal du Seminaire TAD/IDD. Théorie Anthropologique du Didactique \& Ingénierie Didactique du Développement, 2013. Disponível em: http://yves.chevallard.free.fr/spip/spip/IMG/pdf/journal-tad-idd-2012-2013-5.pdf.

CHEVALLARD, Yves. A Teoria Antropológica do Didático Face ao Professor de Matemática. In: ALMOULOUD et al. A Teoria Antropológica do Didático: princípios e fundamentos. Curitiba, Editora: CRV, 2018.1 a Edição. Curitiba, PR: CRV, 2018. p. 31-49.

CORICA, Ana Rosa. (2018). Análisis de la gestión de un dispositivo didáctico formulado en el marco de la TAD. Revista Eletrônica de Educação Matemática, 13(2), 54-71. 2018. doi: https://doi.org/10.5007/1981-1322.2018v13n2p54.

FARIAS, Luís Marcio Santos. Étude des interrelations entre les domaines numérique, algébrique et géométrique dans l'enseignement des mathématiques au secondaire: une analyse des pratiques enseignantes en classes de troisième et de seconde. 2010. Tese (Doutorado) - Universidade de Montpellier 2, France, 2010.

NASCIMENTO JÚNIOR, José Vieira, FARIAS, Luís Marcio Santos, \& CARVALHO, Edmo Fernandes Carvalho. Chronogenesis: how to cope with "unpredictability"? Work presented at the Intensive Research Programme: Advances in the Anthropological Theory of the Didactic and Their Consequences in Curricula and in Teacher Education, Advanced Course 4: Research in Didactics at 
University Level. Centre de Recerca en Matematica, Universitat Autònoma de Barcelona. July 15 to 26, 2019, Barcelona, Spanish.

SEEDF, Educa DF. Teleaula Escola em Casa. 2020 (48:28 - 1h 02:31). Disponível: https://www.youtube.com/watch?v=7sVVBo3MT1A. Acesso em: 05 de mai. 2020.

TROUCHE, Luc. Teaching mathematics in a time of pandemic. Communication answering an invitation from Iranian Telegram channel "Teacher as Lifelong learner". 2020. Disponível em: https://www.academia.edu/42992202/Teaching_mathematics_in_a_time_of_pandemic?email_work _card=view-paper. Acesso em: 11 de mai. 2020.

UNESCO. A Comissão Futuros da Educação da UNESCO apela ao planejamento antecipado contra o aumento das desigualdades após a COVID-19. 2020. Disponível em:

https://fr.unesco.org/news/commission-lavenir-leducation-lunesco-appelle-action-concerteecontrer-laggravation-inegalites. Acesso em: 12 mai. 2020.

VALLE, Paulo Dalla; MARCOM, Jacinta Lucia Rizii. Desafios da Prática Pedagógica e as Competências para Ensinar em Tempos de Pandemia. In: Desafios da educação em tempos de pandemia / organizadores: Janete Palú, Jenerton Arlan Schütz, Leandro Mayer. - Cruz Alta, 2020. Disponível em: file:///C:/Users/Jany/Downloads/Livro\%20-

\%20DESAFIOS\%20DA\%20EDUCACAO\%20EM\%20TEMPOS\%20DE\%20PANDEMIA.pdf Acesso em: 20 nov. 2020.

WORLD HEALTH ORGANIZATION. (2020). COVID-19 Strategy up Date. World Health Organization [WHO], 16 de abr. 2020. Disponível em: https://www.who.int/docs/defaultsource/coronaviruse/covid-strategy-update-14april2020.pdf?sfvrsn=29da3ba0_19. Acesso em: 12 mai. 2020. 